\title{
Measuring spike train reliability
}

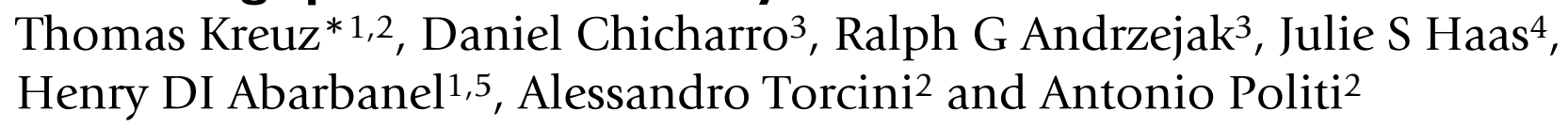

\begin{abstract}
Address: ${ }^{1}$ Institute for Nonlinear Sciences, University of California, San Diego, USA, ${ }^{2}$ Institute for Complex Systems, CNR, Sesto Fiorentino, Italy, ${ }^{3}$ Department of Information and Communication Technologies, Universitat Pompeu Fabra, Barcelona, Spain, ${ }^{4}$ Center for Brain Science, Harvard University, USA and ${ }^{5}$ Department of Physics and Marine Physical Laboratory (Scripps Institution of Oceanography), University of California, San Diego, USA

Email: Thomas Kreuz* - tkreuz@ucsd.edu

* Corresponding author
\end{abstract}

from Seventeenth Annual Computational Neuroscience Meeting: CNS*2008 Portland, OR, USA. 19-24 July 2008

Published: II July 2008

BMC Neuroscience 2008, 9(SuppI I):P30 doi: I0.I I86/I47I-2202-9-SI-P30

This abstract is available from: http://www.biomedcentral.com/I47I-2202/9/SI/P30

(c) 2008 Kreuz et al; licensee BioMed Central Ltd.

Measuring the degree of synchrony between two or more neuronal spike trains is an important tool in order to address issues such as neuronal coding, information transmission and model validation. Another prominent application is to measure the reliability of the response of individual neurons upon repeated presentations of the same stimulus. A number of both multivariate and bivariate measures have been proposed to address this issue. Multivariate approaches include the reliability measures by Hunter and Milton [1] and by Tiesinga [2], while bivariate approaches comprise the Victor-Purpura [3] and the van Rossum [4] distance, as well as the similarity measure proposed by Schreiber et al. [5], and, the most recent proposal, the ISI-distance [6], a method based on relative instantaneous firing rates. These approaches can be applied to multivariate data in a pairwise fashion, e.g., reliability can be defined as the average over all pairwise similarities.

Here, we extend the bivariate ISI-distance to a truly multivariate measure [7]. This extension inherits the distinct properties of the ISI-distance, in particular, it is parameter free and time scale adaptive. In an application to in vitro recordings of cortical cells from rats we show that the multivariate ISI-distance serves as an excellent means to track relative firing patterns in the spike trains. The instantaneous degree of synchrony can be visualized easily, thus rendering this method a good choice for moving window applications on non-stationary neuronal dynamics. In particular, when estimating reliability this property allows the analyst to correlate intervals of high or low synchrony to the respective local stimulus features, which is desirable in many applications. Furthermore, we use a simulated network of Hindemarsh-Rose neurons with predefined clustering [8] as a controlled setting to evaluate the performance of the multivariate ISI-distance in distinguishing different sets consisting of a variable number of spike trains from different clusters. In a comparison with other multivariate approaches, as well as generalizations of several bivariate methods, the method presented here proves to be a very reliable indicator of set balance.

\section{Acknowledgements}

TK has been supported by the Marie Curie Individual Intra-European Fellowship "DEAN", project No 0I I434, DC by the I.U.E. Department of the Generalitat of Catalunya and the European Social Fund, and RGA by the Ramón y Cajal program. JSH acknowledges financial support by the San Diego Foundation.

\section{References}

I. Hunter JD, Milton G, Thomas PJ, Cowan JD: Resonance effect for neural spike time reliability. J Neurophysiol 1998, 80: I 427-I 438.

2. Tiesinga PHE, Sejnowski TJ: Rapid temporal modulation of synchrony by competition in cortical interneuron networks. Neural Comput 2004, 16:25I-275.

3. Victor J, Purpura K: Nature and precision of temporal coding in visual cortex: A metric-space analysis. J Neurophysiol 1996, 76:1310-1326.

4. van Rossum MCW: A novel spike distance. Neural Computation 200I, 13:75I-763.

5. Schreiber S, Fellous JM, Whitmer JH, Tiesinga PHE, Sejnowski TJ: A new correlation-based measure of spike timing reliability. Neurocomputing 2003, 52-54:925-931. 
6. Kreuz T, Haas JS, Morelli A, Abarbanel HDI, Politi A: Measuring spike train synchronization. J Neurosci Methods 2007, 165:151-161.

7. The Matlab source code for calculating and visualizing both the bivariate and the multivariate ISI-distance as well as information about the implementation can be found under [http://inls.ucsd.edu/ kreuz/Source-Code/Spike-Sync.html]

8. Morelli A, Grotto RL, Arecchi FT: Neural coding for the retrieval of multiple memory patterns. Biosystems 2006, 86:100-109.

Publish with Bio Med Central and every scientist can read your work free of charge

"BioMed Central will be the most significant development for disseminating the results of biomedical research in our lifetime. "

Sir Paul Nurse, Cancer Research UK

Your research papers will be:

- available free of charge to the entire biomedical community

- peer reviewed and published immediately upon acceptance

- cited in PubMed and archived on PubMed Central

- yours - you keep the copyright

Submit your manuscript here:

http://www.biomedcentral.com/info/publishing_adv.asp 